among participants using observed variables, was used to differentiate "pain phenotypes" considering sex, body mass index (BMI), emotional problems, comorbidities, number of painful sites and knee structural damage on MRI.

Results: Three pain phenotypes were identified: Class 1: high levels of emotional problems and low levels of structural damage (24\%); Class 2: high levels of structural damage and low levels of emotional problems (20\%); Class 3: relatively low levels of emotional problems and low levels of structural damage (56\%). People within Class 1 were more likely to be female, had greater BMI, lower education level, more comorbidities, more severe knee pain and more painful sites as compared to Class 2 and Class 3. Furthermore, WOMAC pain scores and number of painful sites were consistently greater at baseline, 2.6, 5.1 and 10.7 years in Class 1 than Class 2 and Class 3 (all $\mathrm{P}<0.05$ ).
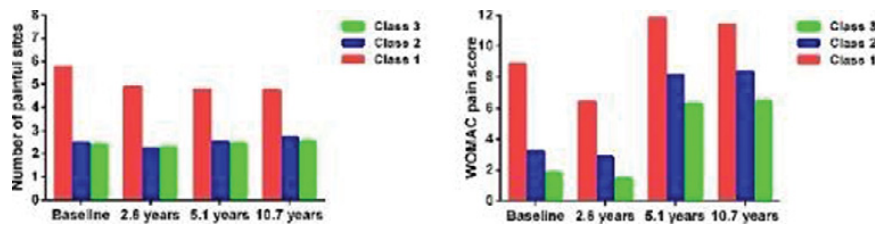

Conclusions: Psychological and structural factors interact with each other to influence pain perception.

Disclosure of Interest: None declared

DOI: 10.1136/annrheumdis-2017-eular.3033

\section{THU0700 IMMUNOGENICITY IN PATIENTS SWITCHING FROM STABLE ORIGINATOR INFLIXIMAB TREATMENT TO CT-P13: ANALYSES ACROSS SIX DISEASES FROM THE 52-WEEK RANDOMIZED NOR-SWITCH STUDY}

G.L. Goll $^{1}$, I.C. Olsen ${ }^{1}$, K.E.A. Lundin ${ }^{2}$, K.K. Jørgensen ${ }^{3}$, M. Lorentzen ${ }^{4}$, R.A. Klaasen ${ }^{5}$, D.J. Warren ${ }^{5}$, C. Mørk ${ }^{6}$, J. Jahnsen ${ }^{3}$, E.A. Haavardsholm ${ }^{1}$, T.K. Kvien ${ }^{1}$, N. Bolstad ${ }^{5}$ on behalf of The NOR-SWITCH study group. ${ }^{1}$ Dept of Rheumatology, Diakonhjemmet Hospital; ${ }^{2}$ Gastroenterology, Oslo University Hospital, Oslo; ${ }^{3}$ Gastroenterology, Akershus University Hospital, Lørenskog; ${ }^{4}$ Dermatology; ${ }^{5}$ Biochemistry DNR, Oslo University Hospital, Oslo;

${ }^{6}$ Dermatology, St Olav University Hospital, Trondheim, Norway

Background: TNF-inhibitors (TNFi) have improved treatment of Crohn's disease (CD), ulcerative colitis (UC), spondyloarthritis (SpA), rheumatoid arthritis (RA), psoriatic arthritis (PsA) and chronic plaque psoriasis (Ps). The NOR-SWITCH study was funded by the Norwegian government to investigate if switching from originator infliximab (Remicade ${ }^{\circledR}$, INX) to biosimilar CT-P13 $\left(\right.$ Remsima $\left.^{\circledR}\right)$, is safe. Previously, the primary analyses of the pooled indications have been published ${ }^{1}$. Immunogenicity is associated with treatment failure and has been of particular concern in switching ${ }^{2}$.

Objectives: The NOR-SWITCH study aimed to assess if immunogenicity to infliximab differed between patients treated with continous INX vs patients switched to CT-P13.

Methods: The study was designed as a 52-week randomized, double-blind, non-inferiority, phase IV trial. Adult patients with a diagnosis of CD, UC, SpA, RA, PsA or Ps on stable treatment with the originator infliximab were eligible. Patients were randomized 1:1 to either continued INX or switch to CT-P13 treatment, using unchanged dosing regimen. Trough drug levels and neutralizing anti-drug antibodies (ADAb) measurements were done prior to every infusion, but results were not reported during the study. Assays for drug serum levels and ADAb are fully automated on the AutoDELFIA ${ }^{\circledR}$ (PerkinElmer, Waltham, MA) immunoassay platform. Results: Twenty patients entered the study with detectable ADAb (9 in INX arm, 11 in CT-P13 arm). 36 additional patients developed detectable incident ADAb during the 52-week study period (17 in INX arm, 19 in CT-P13 arm). Incident $A D A b$ in each disease are shown in the table. Patients with detectable ADAb at any time during the study period were more likely to discontinue study drug treatment $(7 / 26(26.9 \%)$ in INX arm, 5/30 (16.7\%) in CT-P13 arm) than patients without detectable ADAb (17/214 (7.9\%) in INX arm, 13/210 (6.2\%) in CT-P13 arm) $(\mathrm{p}=0.001)$.

Incident ADAb during study period (total number of patients), Full Analysis Set

\begin{tabular}{lcc}
\hline & \multicolumn{1}{c}{ INX } & CT-P13 \\
\hline All patients in study & $17(241) 7.1 \%$ & $19(240) 7.9 \%$ \\
RA patients & $6(39) 15.4 \%$ & $2(38) 5.3 \%$ \\
SPA patients & $2(45) 4.4 \%$ & $5(46) 10.9 \%$ \\
PSA patients & $1(14) 7.1 \%$ & $0(16)$ \\
UC patients & $5(47) 10.6 \%$ & $8(46) 17.4 \%$ \\
CD patients & $3(75) 3.9 \%$ & $4(77) 5.2 \%$ \\
Ps patients & $0(18)$ & $0(17)$ \\
\hline
\end{tabular}

Conclusions: The NOR-SWITCH study demonstrated similar immunogenicity in patients switched to CT-P13 vs those who continued INX treatment, supporting that switch does not influence ADAb formation. Presence of ADAb was associated with termination of study treatment.

References:

[1] Jørgensen KK, Olsen IC, Goll GL et al. Switching from originator infliximab to biosimilar CT-P13 compared to maintained treatment with originator infliximab (NOR-SWITCH): a 52-week randomised double-blind non-inferiority trial. The Lancet, in press.

[2] Dörner T, Kay J. Biosimilars in rheumatology: current perspectives and lessons learnt. Nat Rev Rheumatol 2015 Dec;11(12):713-24.

Disclosure of Interest: G. Goll Consultant for: Novartis, Pfizer, Orion Pharma, AbbVie, I. Olsen: None declared, K. Lundin Consultant for: Orion Pharma, MSD, Takeda, K. Jørgensen Consultant for: Orion Pharma, AbbVie, Tillott, Intercept, M. Lorentzen: None declared, R. Klaasen: None declared, D. Warren: None declared, C. Mørk Consultant for: Novartis, LeoPharma, ACOhud, AbbVie, Galderma Nordic, Cellgene, J. Jahnsen Consultant for: Orion Pharma, Celltrion, Pfizer, MSD, AbbVie, Takeda, Napp Pharm, AstroPharma, E. Haavardsholm Consultant for: AbbVie, UCB, Pfizer, MSD, Roche, T. Kvien Consultant for: Biogen, BMS, Boehringer Ingelheim, Celltrion, Eli Lily, Epirus, Hospira, Merck-Serono, Novartis, Orion Pharma, Pfizer, Sandoz, UCB, N. Bolstad: None declared

DOI: 10.1136/annrheumdis-2017-eular.4112

\section{THU0701 THE EFFECTS OF STRUCTURAL DAMAGE ON FUNCTIONAL DISABILITY IN PSORIATIC ARTHRITIS}

A. Kerschbaumer, F. Alasti, J.S. Smolen, D. Aletaha. Department of Medicine III (Chairman: Prof. Josef Smolen, MD), Medical University of Vienna, Vienna, Austria

Background: Functional outcomes are central in patients with chronic inflammatory musculoskeletal diseases. It has been shown in rheumatoid arthritis that functional outcomes are impaired in the presence of structural damage, a finding that has not yet been investigated in psoriatic arthritis (PsA), which has a more complex phenotype than rheumatoid arthritis (RA).

Objectives: To quantify the association of radiographic damage with physical function in PsA patients.

Methods: We analysed patients enrolled in the GO-REVEAL study ${ }^{1}$ who had received golimumab. We obtained modified Sharp-van-der-Heijde scores (mSvDHS) from X-rays, performed at week 0, 24, 52 and week $104(n=262)$. In longitudinal data analysis, we then used generalized estimating equations (GEE) on all patients in DAPSA remission $(n=96)$, utilising all their remission visits, whereby the health assessment questionnaire (HAQ) disability index of each patients visit was used as dependent variable and mSvDHS, joint space narrowing (JSN) and erosion (ERO) scores, respectively, were used as independent variables in separate models.

To analyse effects of structural damage on changeability of functional limitations, we identified a subgroup of patients who had functional limitations at baseline $(H A Q \geq 1)$ and who showed a major response of DAPSA (improvement of $\geq 85 \%$ from baseline). In this model we assess the effect of mSvDHS on changes in $H A Q$, while adjusting for $H A Q$ at baseline $(n=54)$.

As validation cohort, we analysed a routine clinic PsA cohort with complete cDAPSA (the clinical version of the DAPSA without CRP) and mSvDHS $(n=99)$. A cDAPSA cutoff of $\leq 4$ was used to define the remission cohort in an analogous way as decribed above $(n=32)$.

Results: As shown in table 1 and visualised in figure $1 \mathrm{~A}$, for patients in DAPSA remission, significant effects were seen for mSvDHS, JSN and ERO. These results could be confirmed in the validation cohort with patients achieving cDAPSA remission and showed a significant association of $\mathrm{HAQ}$ and $\mathrm{mSvDHS}$ (Estimate $=0.0044, p=0.0176$ ) as well as JSN (Estimate $=0.0078, p=0.0165$ ).

In the second analysis, looking at patients achieving DAPSA major response, again, results were significant for the association total mSVDHS and JSN. Additionally, higher estimates of JSN, compared to mSvDHS could be observed, with relative $\mathrm{HAQ}$ change as outcome parameter (see table 1 and figure $1 \mathrm{~B}$ ).

Table 1. Association of radiographic damage and HAQ in separate GEE models

\begin{tabular}{|c|c|c|c|c|}
\hline \multirow{2}{*}{$\begin{array}{l}\text { Dependent variable } \\
\text { Independent variable }\end{array}$} & \multicolumn{2}{|c|}{$\begin{array}{c}\text { DAPSA remission }(n=96) \\
\text { HAQ }\end{array}$} & \multicolumn{2}{|c|}{$\begin{array}{l}\text { DAPSA Major Response }(n=54) \\
\text { relative HAQ change }{ }^{\star}\end{array}$} \\
\hline & Estimate & $p$ & Estimate & $\mathrm{p}$ \\
\hline $\mathrm{mSV}$ & $0.0037(0.0018$ to 0.0055$)$ & $<0.001$ & $-0.0014(-0.0027$ to -0.0002$)$ & 0.024 \\
\hline Erosion & $0.0054(0.0021$ to 0.0088$)$ & 0.001 & $-0.0021(-0.0043$ to 0.0002$)$ & 0.075 \\
\hline JSN & $0.0095(0.0057$ to 0.013$)$ & $<0.001$ & $-0.0039(-0.0067$ to -0.0012$)$ & 0.005 \\
\hline
\end{tabular}

${ }^{*}$ Adjusted for $\mathrm{HAQ}$ at baseline.
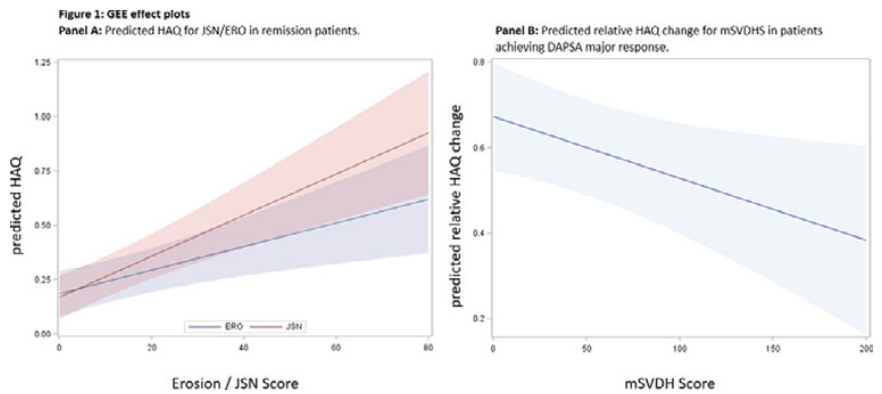

Conclusions: Our results suggest that in JSN is functionally more important than 